\title{
AVALIAÇÃO QUALI-QUANTITATIVA DE ESPÉCIES ARBÓREAS NO PERÍMETRO URBANO DA CIDADE DE CORUMBATAÍ DO SUL - PR
}

\author{
QUALITATIVE-QUANTITATIVE ASSESSMENT OF THE ARBOREAL SPECIES IN \\ URBAN PERIMETER OF CORUMBATAI DO SUL CITY - PR
}

\author{
Gabriela Roberta Nardon Meira ${ }^{1}$; Gustavo Guazzeli Medeiros Texeira ${ }^{1}$; \\ Pâmela Roberta Francisquetti Venturin ${ }^{1}$; Pauline Gottstein ${ }^{1}$; Marcelo Galeazzi Caxambu²
}

\section{RESUMO}

Os benefícios da arborização urbana estão condicionados à qualidade de seu planejamento e manejo, visto que o negligenciamento destes resultam em conflitos com os equipamentos urbano, infraestrutura e pedestres. Tendo em vista o exposto, o presente estudo teve como objetivo realizar análise qualiquantitativa de compatibilidade das essências com meio onde estão inseridas, através do censo das espécies arbóreas. Analisou-se 458 indivíduos distribuídos em 36 espécies vegetais, 34 gêneros e 21 famílias botânicas, dentre estas, Poincianella pluviosa var. peltophoroides, Schinus molle e Ligustrum lucidum foram as espécies mais abundantes, representando juntas $75,8 \%$ da arborização urbana. A partir dos resultados obtidos, $P$. pluviosa e $S$. molle foram as espécies que notoriamente apresentaram maiores índices de conflitos entre planta/infraestrutura ao se avaliar, por exemplo, situação da raiz, rede elétrica, interferência no trânsito de pedestres, canteiro ao redor do espécime arbóreo e altura da primeira bifurcação, constatando a necessidade de manejo adequado da arborização, visando tornar o indivíduo arbóreo compatível com o meio, causando o mínimo conflito possível com equipamentos urbanos, passagem de veículos e pedestres.

Palavras-chave: Análise quali-quantitativa; Arborização urbana; Planejamento urbano.

\begin{abstract}
The benefits of urban afforestation are conditioned to the quality of its planning and management, since the neglect of these results in conflicts with the public equipment, infrastructure and pedestrians. In view of the above, the present study aimed to make qualitative and quantitative analysis of the compatibility of the essences with the environment in which they are inserted, through the census of arboreal species. It was examined 458 individuals distributed in 36 plant species, 34 genera and 21 botanical families, among these, Poincianella pluviosa var. peltophoroides, Schinus molle and Ligustrum lucidum were the most abundant species, representing $75.8 \%$ of joints urban afforestation. From the results obtained, $P$. pluviosa and $S$. molle were species that notoriously showed higher rates of conflicts between plant/infrastructure when assessing, for example, situation of the root, electrical network, interference in pedestrian traffic, free area surroundings of the specimen and height of first bifurcation, noting the need for appropriate management of afforestation, aiming to make the individual tree compatible to the environment, causing the least possible conflict with public equipment, passage of vehicles and pedestrians and a better development of the plant.
\end{abstract}

Keywords: Qualitative and quantitative analysis; Urban afforestation; Urban planning

Recebido em 18.12.2015 e aceito em 04.02.2016

1 Graduando do curso de Engenharia Ambiental, Universidade Tecnológica Federal do Paraná (UTFPR). Campo Mourão/Paraná. Emails de contato: gabrielameira@alunos.utfpr.edu.br; gustavoteixeira@alunos.utfpr.edu.br; pamelaventurin5@hotmail.com; paulinegottstein@hotmail.com

2 Engenheiro Florestal, Dr. Professor do Departamento de Engenharia Ambiental da Universidade Tecnológica Federal do Paraná, Campo Mourão/Paraná. Email: mcaxambu@utfpr.edu.br 


\section{INTRODUÇÃO}

A arborização urbana atua como um mecanismo de conforto humano, visto que proporciona sombra a pedestres e veículos, reduz níveis de ruídos, controla os níveis de poluentes, reduz a amplitude térmica, além de proporcionar melhoria na estética da cidade e abrigo à avifauna (MASCARÓ; MASCARÓ, 2002).

Os benefícios da arborização de ruas e avenidas estão condicionados à qualidade de seu planejamento, entretanto, na maioria das cidades brasileiras, observa-se 0 negligenciamento referente à arborização urbana dentro do planejamento e elaboração dos planos diretores das cidades, onde a maioria é apresentada apenas para cumprir com as obrigações civis, equivocando-se sobre a real importância do planejamento da arborização urbana, não tendo assim, o plano diretor, função ambiental relevante (BRUN et al., 2008). Desta forma, se torna evidente a necessidade da realização de estudos nessa área (BATISTEL et al., 2009).

De acordo com Silva et al. (2006), as características e parâmetros a serem avaliados dentro de um planejamento urbano devem abordar critérios como a localização do espécime arbóreo e também características com relação à espécie e o meio, como largura das ruas e passeios, espaçamento no plantio, pavimentação e presença de distribuição elétrica.

O plantio de espécies nativas na arborização de parques, praças, jardins e passeios urbanos é uma prática desejável, com importantes ganhos ambientais, estéticos e culturais para as cidades (MACHADO et al., 2006). É preferível que as espécies escolhidas para a arborização não possuam espinhos e/ou acúleos e não tenham potencial alergênico e/ou tóxico, entretanto, é importante que estas possuam raízes compatíveis com o local do plantio, que possuam madeira com alta resistência evitando quedas de galhos, apresentem baixa quantidade de deposição de biomassa (principalmente frutos), apresentem períodos de inflorescência ao longo do ano com o intuito de atrair polinizadores e/ou dispersores (PIVETTA; SILVA FILHO, 2002), e que não apresentem potencial exótico invasor (BIONDI; MACEDO, 2008).

Além dessas características faz-se necessário, para melhor desenvolvimento da planta, realizar um manejo adequado das espécies, desde a produção, plantio e crescimento da muda (PIVETTA; SILVA FILHO, 2002), visando a compatibilidade com os equipamentos urbanos.

Tendo em vista o exposto, o presente trabalho apresenta o levantamento das espécies utilizadas na arborização viária de Corumbataí do Sul - Paraná, avaliando qualiquantativamente a compatibilidade dos espécimes com equipamentos urbanos e as infraestruturas, com o objetivo de fornecer subsídios para autoridades municipais 
estabelecerem um manejo adequado da arborização, tornando o indivíduo arbóreo compatível com o local onde está inserido.

\section{MATERIAL E MÉTODOS}

\section{Caracterização da área de estudo}

A cidade de Corumbataí do Sul situa-se na região Centro-oeste do Estado do Paraná, estando entre as coordenadas $24^{\circ} 05^{\prime} 59^{\prime \prime}$ e $24^{\circ} 06^{\prime} 20^{\prime \prime}$ de latitude sul e entre $52^{\circ} 06^{\prime} 50^{\prime \prime}$ e $52^{\circ} 07^{\prime} 41^{\prime \prime}$ de longitude oeste (Figura 1). Possui altitude média de $600 \mathrm{~m}$ e uma área territorial de $169,528 \mathrm{~km}^{2}$, contando com uma população estimada de 3.749 habitantes, fazendo limite com Campo Mourão, Peabiru e Barbosa Ferraz (IPARDES, 2015).

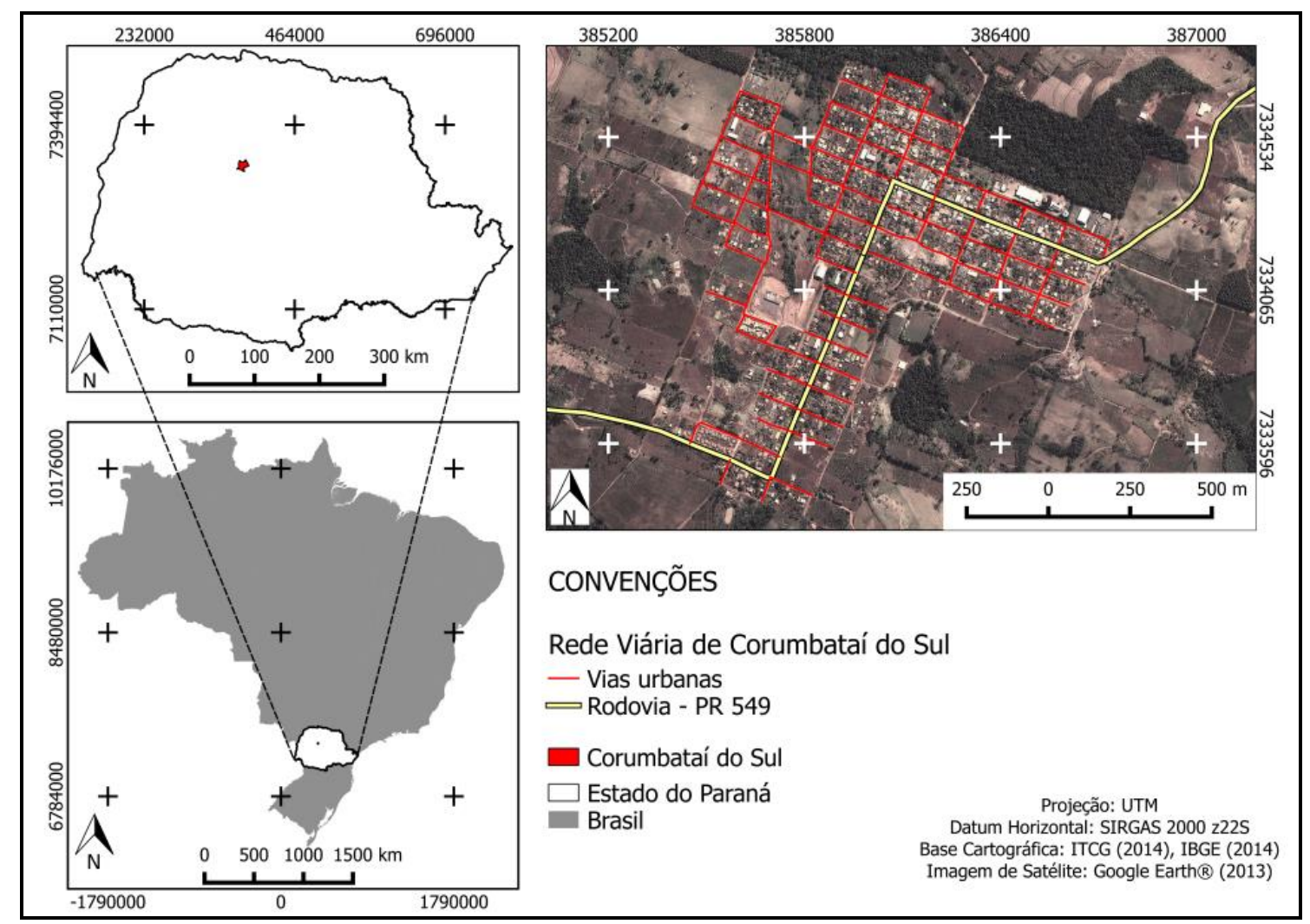

Figura 1. Localização e caracterização das vias do Município de Corumbataí do Sul, Paraná

Figure 1. Location and characterization of the streets in the Municipality of Corumbataí do Sul, Paraná

Segundo a classificação climática de Köppen-Geiger, o município possui clima subtropical mesotérmico (Cfa) com temperatura inferior a $18^{\circ} \mathrm{C}$ no mês mais frio e temperatura média acima de $22^{\circ} \mathrm{C}$ no mês mais quente (CAVIGLIONE et al., 2000). 
Analisando a distribuição das unidades fitogeográficas do Estado do Paraná proposta por Roderjan et al. (2002), Corumbataí do Sul pertence ao Bioma Mata Atlântica, com ocorrência predominante da Floresta Estacional Semidecidual.

O perímetro urbano do município é caracterizado por duas avenidas principais, Av. Xavantes e Av. Tupi, e por 30 ruas, sendo que duas delas, Rua Caramuru e Rua Guarani, fazem parte da PR 549. Um dos locais turísticos de Corumbataí do Sul é o monumento do Cristo Redentor, que localiza-se dentro do perímetro urbano, além de contar com a praça São Pedro, popularmente frequentada devido aos eventos realizados no local.

\section{Procedimentos metodológicos}

A coleta dos dados referentes à arborização urbana de Corumbataí do Sul foi realizada durante o período de setembro a outubro de 2015.

No estudo foram coletadas todas as espécies arbóreas com comprimento à altura do peito (CAP) maiores que $20 \mathrm{~cm}$, metodologia esta utilizada no trabalho de Miranda e Carvalho (2009), uma vez que plantas com CAP inferior a este valor podem mascarar dados referentes a eventuais danos e conflitos em função de sua juventude. Foram consideradas as espécies presentes nos canteiros centrais e calçadas de passeio das vias públicas, incluindo neste critério plantas arbustivas e palmeiras, excetuando-se aquelas plantadas no interior de praças e logradouros públicos.

Para conduzir a identificação dos espécimes arbóreos, foram coletadas amostras de material botânico, preferencialmente fértil, sendo posteriormente enumeradas e dispostas em sacos plásticos para então serem encaminhadas ao Herbário da Universidade Tecnológica Federal do Paraná Câmpus Campo Mourão (HCF) e identificados.

A classificação de famílias botânicas seguiu APG III (2009) e os epítetos específicos e autores seguiram a Lista da Flora do Brasil (2015).

A análise da compatibilidade foi realizada pela técnica de inventário arbóreo por meio de censo, mediante o preenchimento de formulários para registro dos dados com caráter qualitativo e quantitativo, adaptado de Martins et al. (2011) e Silva, Silveira e Teixeira (2008). Os itens analisados estão descritos a seguir:

A. Número controle: atribuição de um número para controle de dados a cada espécie (nome científico e comum/vulgar);

B. Presença de exótica invasora: verificou-se entre os indivíduos presentes na arborização urbana, quais estavam classificados como invasores e exóticos invasores para o Paraná, de acordo com a Portaria IAP no 59 de 2015, que estabelece em seu Anexo I a lista de plantas exóticas invasoras para o Estado; 
C. Localização do espécime: se localizado junto à guia, junto à divisa do lote ou ainda se está centrado na calçada;

D. Pavimento em que a árvore está inserida: se em passeio com solo exposto, cimento, pedra, cerâmica, ladrilho hidráulico ou grama;

E. Situação da raiz: análise quanto às condições visuais da raiz, dividindo-se em:

a. Não há afloramento: quando a raiz se encontra totalmente subterrânea;

b. Afloramento na calçada: quando a raiz está aflorando, causando visíveis danos ao calçamento;

F. Rede elétrica: análise quanto à presença ou ausência de rede elétrica sobre o espécime arbóreo. Análise quanto à existência de conflitos, caracterizados pelo contato entre o espécime arbóreo e a rede elétrica;

G. Copa: análise visual que consiste da observação da copa da árvore, analisando sua potencial interferência, ou não, no trânsito de pedestres e veículos automotores;

H. Canteiro ao redor do espécime arbóreo: análise quanto ao tamanho da área do canteiro ao redor do espécime arbóreo, sendo dividida em maior que $1 \mathrm{~m}^{2}$ e menor que $1 \mathrm{~m}^{2}$;

I. Altura da primeira bifurcação: mediu-se a altura, classificando em espécimes arbóreos com primeira bifurcação menor que 1,80 m e maior que 1,80 m.

Após coletados todos os dados a partir do preenchimento do formulário, as informações foram tabuladas em planilha do Microsoft Exce组 versão 2007 para posterior realização de análises e interpretações.

\section{RESULTADOS E DISCUSSÃO}

\section{Composição da arborização viária}

A partir do censo realizado na cidade de Corumbataí do Sul (PR), foram contabilizados 458 indivíduos encontrados nos canteiros centrais e calçadas de passeio das vias públicas, distribuídos em 36 espécies vegetais, 34 gêneros e 21 famílias botânicas (Tabela 1). 
Tabela 1. Distribuição quantitativa e atributos analisados das espécies arbóreas ocorrentes nos canteiros centrais e calçadas de passeio das vias públicas na cidade de Corumbataí do Sul, Paraná

Table 1. Quantitative distribution and analyzed attributes of the species in public median strips and sidewalks in city of Corumbataí do Sul, Paraná

\begin{tabular}{|c|c|c|c|c|c|c|c|c|c|c|c|c|c|}
\hline Família / Espécie & $\mathbf{N c}_{\mathrm{c}}$ & Oc & $\begin{array}{c}F \\
(\%)\end{array}$ & $Q_{F}$ & $\begin{array}{l}P_{F} \\
(\%)\end{array}$ & $\begin{array}{l}\text { PFt } \\
(\%)\end{array}$ & Qc & $\begin{array}{l}\mathrm{Pc} \\
(\%)\end{array}$ & $\begin{array}{l}\text { Pct } \\
(\%)\end{array}$ & $Q_{p}$ & $\begin{array}{l}P_{p} \\
(\%)\end{array}$ & $\begin{array}{l}\text { Ppt } \\
(\%)\end{array}$ & $\mathbf{P}$ \\
\hline \multicolumn{14}{|l|}{ Anacardiaceae } \\
\hline Mangifera indica L. & Manga & 9 & 1,96 & 5 & 55,6 & 2,6 & 1 & 11,2 & 0,9 & 4 & 44,5 & 3,0 & $\mathrm{El}$ \\
\hline Schinus molle L. & Chorão & 78 & 17,03 & 27 & 34,6 & 13,7 & 3 & 3,8 & 2,7 & 65 & 83,4 & 49,2 & $\mathrm{~N}$ \\
\hline \multicolumn{14}{|l|}{ Annonaceae } \\
\hline $\begin{array}{l}\text { Annona muricata } \\
\text { Linnaeus }\end{array}$ & Graviola & 1 & 0,22 & 0 & 0 & 0 & 0 & 0 & 0 & 1 & 100 & 0,75 & $\mathrm{E}$ \\
\hline \multicolumn{14}{|l|}{ Apocynaceae } \\
\hline Nerium oleander $\mathrm{L}$. & Espirradeira & 1 & 0,22 & 1 & 100 & 0,5 & 0 & 0 & 0 & 1 & 100 & 0,75 & E \\
\hline Plumeria obtusa L. & Jasmim-manga & 2 & 0,44 & 0 & 0 & 0 & 0 & 0 & 0 & 1 & 50 & 0,75 & $\mathrm{E}$ \\
\hline \multicolumn{14}{|l|}{ Arecaceae } \\
\hline $\begin{array}{l}\text { Archontophoenix } \\
\text { alexandrae H. Wendi. \& } \\
\text { Drude }\end{array}$ & Palmeira-beatriz & 2 & 0,44 & 0 & 0 & 0 & 0 & 0 & 0 & 1 & 50 & 0,75 & $\mathrm{E}$ \\
\hline $\begin{array}{l}\text { Syagrus romazoffiana } \\
\text { (Cham.) Glassman }\end{array}$ & Jerivá & 1 & 0,22 & 1 & 100 & 0,5 & 0 & 0 & 0 & 0 & 0 & 0 & N \\
\hline \multicolumn{14}{|l|}{ Asteraceae } \\
\hline $\begin{array}{l}\text { Licania tomentosa } \\
\text { (Benth) Fritsch }\end{array}$ & Oiti & 19 & 4,15 & 2 & 10,5 & 1,0 & 0 & 0 & 0 & 16 & 84,2 & 12,2 & $\mathrm{E}$ \\
\hline \multicolumn{14}{|l|}{ Bignoniaceae } \\
\hline $\begin{array}{l}\text { Handroanthus } \\
\text { chrysotrichus (Mart. ex } \\
\text { A. DC.) Mattos }\end{array}$ & $\begin{array}{l}\text { Ipê-amarelo- } \\
\text { cascudo }\end{array}$ & 3 & 0,65 & 0 & 0 & 0 & 0 & 0 & 0 & 0 & 0 & 0 & N \\
\hline $\begin{array}{l}\text { Handroanthus } \\
\text { heptaphyllus (Vell.) } \\
\text { Mattos }\end{array}$ & Ipê-rosa & 3 & 0,65 & 1 & 33,3 & 0,5 & 0 & 0 & 0 & 0 & 0 & 0 & N \\
\hline \multicolumn{14}{|l|}{ Combretaceae } \\
\hline Terminalia catappa L. & $\begin{array}{l}\text { Chapéu-de- } \\
\text { praia }\end{array}$ & 6 & 1,31 & 2 & 33,3 & 1,0 & 0 & 0 & 0 & 2 & 33,4 & 1,5 & $\mathrm{El}$ \\
\hline \multicolumn{14}{|l|}{ Fabaceae } \\
\hline Bauhinia variegata $\mathrm{L}$. & Pata-de-vaca & 1 & 0,22 & 0 & 0 & 0 & 0 & 0 & 0 & 1 & 100 & 0,75 & $\mathrm{E}$ \\
\hline \multirow{5}{*}{$\begin{array}{l}\text { Cassia fistula L. } \\
\text { Delonix regia (Bojer ex } \\
\text { Hook.) Raf. } \\
\text { Inga marginata Wild. } \\
\text { Poincianella pluviosa } \\
\text { var. peltophoroides } \\
\text { (Benth.) L.P. Queiroz } \\
\text { Lamiaceae }\end{array}$} & Cássia-imperial & 1 & 0,22 & 0 & 0 & 0 & 0 & 0 & 0 & 1 & 100 & 0,75 & $\bar{E}$ \\
\hline & Flamboyant & 2 & 0,44 & 2 & 100 & 1,0 & 1 & 50 & 0,9 & 0 & 0 & 0 & E \\
\hline & Ingá-mirim & 1 & 0,22 & 0 & 0 & 0 & 0 & 0 & 0 & 1 & 100 & 0,75 & $\mathrm{~N}$ \\
\hline & Sibipiruna & 221 & 48,25 & 140 & 63,3 & 71,1 & 90 & 40,7 & 81,1 & 6 & 2,7 & 4,6 & $\mathrm{E}$ \\
\hline & & & & & & & & & & & & & \\
\hline Duranta vestita Cham. & Pingo-de-ouro & 1 & 0,22 & 0 & 0 & 0 & 0 & 0 & 0 & 1 & 100 & 0,75 & $\mathrm{~N}$ \\
\hline \multicolumn{14}{|l|}{ Lauraceae } \\
\hline $\begin{array}{l}\text { Cinnamomum verum J. } \\
\text { Presl }\end{array}$ & Canela & 1 & 0,22 & 0 & 0 & 0 & 0 & 0 & 0 & 1 & 100 & 0,75 & $E$ \\
\hline \multicolumn{14}{|l|}{ Lytraceae } \\
\hline Lagerstroemia indica L. & Extremosa & 1 & 0,22 & 0 & 0 & 0 & 0 & 0 & 0 & 1 & 100 & 0,75 & E \\
\hline \multicolumn{14}{|l|}{ Malvaceae } \\
\hline $\begin{array}{l}\text { Hibiscus rosa-sinensis } \\
\text { L. }\end{array}$ & Hibisco & 10 & 2,18 & 3 & 30 & 1,5 & 0 & 0 & 0 & 10 & 100 & 7,6 & $\mathrm{E}$ \\
\hline Pachira glabra Pasq. & Paineira & 1 & 0,22 & 1 & 100 & 0,5 & 0 & 0 & 0 & 1 & 100 & 0,75 & $\mathrm{E}$ \\
\hline \multicolumn{14}{|l|}{ Melastomataceae } \\
\hline $\begin{array}{l}\text { Tibouchina granulosa } \\
\text { (Desr.) Cogn }\end{array}$ & Quaresmeira & 2 & 0,44 & 0 & 0 & 0 & 0 & 0 & 0 & 1 & 50 & 0,75 & $\mathrm{E}$ \\
\hline \multicolumn{14}{|l|}{ Meliaceae } \\
\hline Cedrella fissilis Vell. & Cedro & 1 & 0,22 & 0 & 0 & 0 & 1 & 100 & 0,9 & 0 & 0 & 0 & $\mathrm{~N}$ \\
\hline Melia azedarach L. & Santa-bárbara & 1 & 0,22 & 0 & 0 & 0 & 0 & 0 & 0 & 1 & 100 & 0,75 & El \\
\hline Moraceae & & & & & & & & & & & & & \\
\hline
\end{tabular}




\begin{tabular}{|c|c|c|c|c|c|c|c|c|c|c|c|c|c|}
\hline $\begin{array}{l}\text { Artocarpus } \\
\text { heterophyllus Lam. }\end{array}$ & Jaca & 1 & 0,22 & 0 & 0 & 0 & 1 & 100 & 0,9 & 1 & 100 & 0,75 & $E$ \\
\hline Ficus benjamina L. & $\begin{array}{l}\text { Figueira- } \\
\text { variegata }\end{array}$ & 17 & 3,71 & 9 & 52,9 & 4,6 & 13 & 76,5 & 11,7 & 5 & 29,5 & 3,8 & $E$ \\
\hline \multicolumn{14}{|l|}{ Myrtaceae } \\
\hline Eugenia uniflora L. & Pitanga & 1 & 0,22 & 0 & 0 & 0 & 0 & 0 & 0 & 1 & 100 & 0,75 & $\mathrm{~N}$ \\
\hline $\begin{array}{l}\text { Myrciaria cauliflora } \\
\text { (Mart.) O. Berg }\end{array}$ & Jaboticaba & 1 & 0,22 & 0 & 0 & 0 & 0 & 0 & 0 & 1 & 100 & 0,75 & $\mathrm{~N}$ \\
\hline Psidium guajava L. & Goiaba & 3 & 0,65 & 1 & 33,3 & 0,5 & 0 & 0 & 0 & 3 & 100 & 2,3 & $\mathrm{El}$ \\
\hline \multicolumn{14}{|l|}{ Oleaceae } \\
\hline $\begin{array}{l}\text { Ligustrum lucidum W.T } \\
\text { Aiton }\end{array}$ & Ligustro & 52 & 11,35 & 0 & 0 & 0 & 0 & 0 & 0 & 1 & 1,9 & 0,75 & $E$ \\
\hline \multicolumn{14}{|l|}{ Proteaceae } \\
\hline $\begin{array}{l}\text { Grevillea robusta A } \\
\text { Cunn. ex. R. Br. }\end{array}$ & Grevilha & 1 & 0,22 & 1 & 100 & 0,5 & 0 & 0 & 0 & 0 & 0 & 0 & El \\
\hline \multicolumn{14}{|l|}{ Rosaceae } \\
\hline $\begin{array}{l}\text { Eriobotrya japonica } \\
\text { (Thunb.) Lindl. }\end{array}$ & Ameixa-amarela & 2 & 0,44 & 0 & 0 & 0 & 0 & 0 & 0 & 1 & 50 & 0,75 & El \\
\hline $\begin{array}{l}\text { Prunus persica (L.) } \\
\text { Batsch }\end{array}$ & Pêssego & 1 & 0,22 & 0 & 0 & 0 & 0 & 0 & 0 & 0 & 0 & 0 & $E$ \\
\hline Prunus serrulata Lindl. & $\begin{array}{l}\text { Cerejeira-do- } \\
\text { japão }\end{array}$ & 1 & 0,22 & 0 & 0 & 0 & 0 & 0 & 0 & 0 & 0 & 0 & $E$ \\
\hline \multicolumn{14}{|l|}{ Rubiaceae } \\
\hline Genipa americana L. & Genipapo & 5 & 1,08 & 0 & 0 & 0 & 1 & 20 & 0,9 & 0 & 0 & 0 & $\mathrm{~N}$ \\
\hline \multicolumn{14}{|l|}{ Rutaceae } \\
\hline $\begin{array}{l}\text { Citrus } x \text { limon (L.) } \\
\text { Osbeck }\end{array}$ & Limão-rosa & 4 & 0,87 & 1 & 25 & 0,5 & 0 & 0 & 0 & 3 & 75 & 2,3 & $\mathrm{El}$ \\
\hline TOTAL & & 458 & 100 & 197 & & & 111 & & & 132 & & & \\
\hline
\end{tabular}

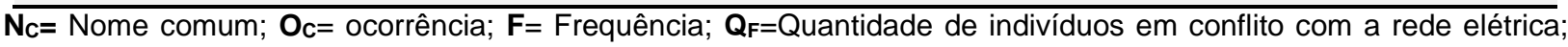
$\mathbf{P}_{\mathbf{F}}=$ Percentagem de indivíduos da espécie em conflitos com a rede elétrica; $\mathbf{P} \mathbf{F t}=$ Percentagem de indivíduos da espécie conflitantes com a fiação em relação ao total; $\mathbf{Q}_{\mathbf{c}}=$ Quantidade de indivíduos em conflito com o calcamento; $\mathbf{P c}_{\mathbf{c}}=$ Percentagem de indivíduos da espécie em conflito com o calçamento; $\mathbf{P c t}=$ Percentagem de indivíduos da espécie conflitantes com o calçamento em relação ao total; $\mathbf{Q}_{\mathbf{P}}=$ Quantidade de indivíduos com a copa em conflito com o trânsito de pedestres; $\mathbf{P P}=$ Percentagem de indivíduos da espécie com a copa em conflito com o trânsito de pedestres; Ppt= Percentagem de indivíduos da espécie com a copa em conflito com o transido de pedestres em relação ao total $\mathbf{P}=$ Procedência; $\mathbf{N}=$ Nativa do Estado do Paraná ; $\mathbf{E}=$ Exótica para o Estado do Paraná; El= Exótica invasora para o Estado do Paraná segundo a Portaria IAP nํ59 de 2015

A família botânica mais abundante foi Fabaceae, perfazendo 49,34\% do total. Este mesmo resultado ocorreu com a pesquisa de Hoppen et al. (2014) e Miranda et al. (2015), respectivamente nas cidades de Farol e Godoy Moreira.

Poincianella pluviosa var. peltophoroides (Benth.) L.P. Queiroz (sibipiruna) foi a espécie mais abundante (48,25\%), seguida de Schinus molle L. (chorão) (17,03\%) e Ligustrum lucidum W.T. Aiton (ligustro) (11,35\%), representando juntas, 76,63\% do total de espécimes encontrados (351 indivíduos) (Tabela 1). Miranda et al. (2015), consideram em seu estudo a norma ISA, que recomenda que cada indivíduo não ultrapasse 10\% a 15\% do total de espécies utilizadas na arborização urbana, o que não se verifica com as espécies $P$. pluviosa e $S$. molle em Corumbataí do Sul (PR).

A partir do supracitado, pode-se verificar que na arborização urbana de Corumbataí do Sul ocorre a utilização de muitos indivíduos de poucas espécies, segundo Martins et al. (2011), isto indica que a população arbórea torna-se mais suscetível ao ataque de pragas e doenças. 


\section{Ocorrência de Plantas Exóticas Invasoras}

De acordo com a Portaria IAP no 59 de 2015, que estabelece em seu Anexo I a lista de plantas exóticas invasoras do Estado do Paraná, dentre as quais estão presentes na cidade sete destas, sendo elas, Mangifera indica L. (manga) (nove indivíduos), Terminalia catappa L. (chapéu-de-praia) (seis indivíduos), Melia azedarach L. (santa-bárbara) (um indivíduo), Psidium guajava L. (goiaba) (três indivíduos), L. lucidum (52 indivíduos), Grevillea robusta A Cunn. ex. R. Br. (grevilha) (um indivíduo), Eriobotrya japonica (Thunb.) Lindl. (ameixa-amarela) (dois indivíduos) e Citrus $x$ limon (L.) Osbeck (limão-rosa) (quatro indivíduos), totalizando 17,03\% dos espécimes coletados.

Considerando os estudos realizados por Miranda et al. (2015) em Godoy Moreira (PR), por Hoppen et al. (2014) em Farol (PR) e por Locastro et al. (2014) em Cafeara, foram encontrados concomitantemente as espécies exóticas invasoras do Estado do Paraná, $M$. indica, T. catappa, M.azedarach, P. guajava, E. japonica, L. lucidum e C. x limon o que corrobora com o coletado em Corumbataí do Sul. Tal fato demonstra a semelhança existente no planejamento da arborização urbana entre cidades de pequeno porte do Estado do Paraná.

No entanto, em grandes cidades também são encontradas algumas dessas espécies. No estudo de Biondi e Macedo (2008) na cidade de Curitiba (PR), foram encontradas sete espécies consideradas exóticas invasoras para a região de Curitiba, que segundo os autores, torna-se preocupante visto que as espécies exóticas invasoras que compõem a arborização, tanto de ruas como de áreas verdes do município, podem suprimir ou comprometer o estabelecimento das demais espécies. Desta forma, Biondi e Macedo (2008), alertam a importância de evitar o uso de tais espécies no planejamento de arborização urbana e coibir tanto o plantio como a produção de mudas, além dos técnicos municipais estarem sempre atualizados a fim de promover o mais adequado manejo.

No estudo realizado por Sampaio e Angellis (2008) nas vias públicas de Maringá (PR), a população de L. lucidum representa $2,78 \%$ da população encontrada, no entanto, esta percentagem é menor do que a encontrada na arborização urbana de Corumbataí do Sul, que apresentou $11,35 \%$ de frequência. Já na pesquisa realizada por Hoppen et al. (2014) em Farol (PR), foi encontrada uma frequência ligeiramente maior de L. lucidum, representando 13,30\%. Estes dados denotam um uso excessivo desta espécie, considerada exótica invasora pela Portaria IAP o 59 de 2015, além de ser considerada tóxica, o que reflete a falta de critérios e estudos sobre o histórico das espécies que serão utilizadas na arborização urbana na maior parte dos municípios brasileiros.

Segundo Blum, Borgo e Sampaio (2008), as exóticas invasoras são a segunda maior causa da extinção de espécies no planeta, afetando diretamente a biodiversidade local. Desta 
forma, os conflitos gerados por tais espécies podem atingir desde a agricultura e a pecuária, o abastecimento público de águas, a saúde da população até danos ao ambiente em função do uso generalizado de pesticidas para seu controle.

Todavia, Blum, Borgo e Sampaio (2008), salientam que nem toda espécie exótica traz prejuízos ambientais, pois algumas espécies se mantêm contidas onde foram plantadas, sem se tornarem invasoras por não ter capacidade de se reproduzir e dispersar na região. Desta forma, essas podem ser introduzidas na arborização viária desde que possuem características aplicáveis a esta finalidade. Vale salientar que também existem aquelas que possuem capacidade de se reproduzir e possivelmente se dispersar, podendo tronar-se invasoras, sendo recomendado evitar tal uso dando preferência a flora nativa a fim de valorizá-la.

\section{Localização das árvores}

Quanto à localização geral dos espécimes arbóreos, 14,2\% se encontrava em canteiros centrais e $85,8 \%$ estavam situados em passeios públicos. Destes $85,8 \%, 95,4 \%$ das árvores se encontravam no centro da área destinada aos passeios públicos e o restante junto à guia das vias públicas e junto à divisa do lote. A maior parte dos indivíduos levantados estava localizada em calçadas de cimento (44,76\%), seguido de passeios públicos com solo exposto $(28,6 \%)$, grama $(25,8 \%)$ e o restante em calçadas de pedra, cerâmica e ladrilho hidráulico $(0,84 \%)$.

É importante se conhecer qual o tipo de pavimento que os indivíduos estão inseridos, pois o pavimento da calçada influencia no desenvolvimento da planta, devido ao tipo de material do pavimento interferir na drenagem e compactação do solo que consequentemente afetará a quantidade e qualidade dos nutrientes que estão disponíveis as plantas (MARTINS et al., 2011).

De acordo com Martins et al. (2011), calçadas que apresentam solo exposto de característica argilosa ou calçadas impermeáveis não são muito adequadas dependendo do caso. Em Corumbataí do Sul, estes tipos de calçamento, que apresentam solo exposto e impermeabilidade, representam juntos $73,36 \%$. As calçadas com solo exposto podem sofrer compactação, processos erosivos, aumento do escoamento superficial, podendo acarretar a redução da infiltração de água. Já as calçadas impermeáveis, como as de cimento, com área do canteiro ao redor do espécime arbóreo inadequada pode prejudicar o desenvolvimento da mesma devido a dificuldade na infiltração de água. Portanto, apesar de grande parte das calçadas presentes em Corumbataí do Sul (PR) ser de cimento e com solo exposto, há necessidade de se analisar cada situação individualmente. 


\section{Árvores e calçamento}

A ocorrência de afloramento da raiz sob o calçamento foi evidenciada em $24,2 \%$ dos indivíduos, sendo P. pluviosa a espécie que denotou a maior ocorrência, representando $81,1 \%$ do total de espécies que apresentaram afloramento, seguida de F. benjamina L. (figueiravariegata) (11,7\%) (Tabela 1). Vale salientar que $64,7 \%$ das $P$. pluviosa amostradas estavam inseridas em calçadas de cimento e $35,3 \%$ em áreas abertas, como grama e solo exposto.

No estudo realizado por Locastro et al. (2014) em Cafeara (PR), P. pluviosa também apresentou maiores interferências com calçamento (20,22\%), comprometendo o acesso e circulação de pedestres. Outro fato que pode influenciar nas intensas degradações constatadas nos calçamentos em Corumbataí do Sul, é que $P$. pluviosa possui cerca de $47 \%$ de seus indivíduos inseridos em locais com área do canteiro ao redor do espécime arbóreo menor que $1 \mathrm{~m}^{2}$, tamanho este não recomendado por Pivetta e Silva Filho (2002).

Diante disso, se torna evidente que $P$. pluviosa apresenta maior ocorrência de afloramento das raízes pela falta de espaço necessário para seu desenvolvimento, evidenciando o manejo incorreto das mudas em viveiro, que na maioria das vezes, possuem porte em torno de dois metros quando vão para as ruas, sendo produzidas em embalagens de $400 \mathrm{~cm}^{3}$, o que acaba por propiciar o enovelamento e o cachimbamento das raízes, refletindo posteriormente em problemas com o calçamento quando plantadas.

Sartori e Balderi (2011) indicam que F. benjamina possui tendência de gerar problemas futuros, pois alcança grande porte e apresentam raízes tabulares que crescem para os lados e normalmente ficam expostas. Tais fatos demonstram que $F$. benjamina gera problemas principalmente com calçamento, como constatado por Locastro et al. (2014) em seu estudo em Cafeara, onde 55,2\% destas apresentaram problemas com calçamento, enquanto que em Corumbataí do Sul, observou-se que $76,47 \%$ de $F$. benjamina caracterizaram conflitos com a calçada devido ao afloramento de raiz. Este resultado pode ter ocorrido, pois $58,8 \%$ dos seus indivíduos estavam situados em calçadas de cimento e $47 \%$ em áreas cujo canteiro ao redor do espécime arbóreo eram menores que $1 \mathrm{~m}^{2}$ resultando assim em maiores danos ao calçamento e comprometendo a circulação dos pedestres.

\section{Árvores e rede elétrica}

A rede elétrica está presente sobre 56,3\% dos espécimes arbóreos, diante disso, puderam ser observadas $43 \%$ das árvores da arborização urbana em contato com a rede elétrica, onde $P$. pluviosa e $S$. molle apresentaram os maiores conflitos, representando respectivamente, $71,1 \%$ e $13,7 \%$ (Tabela 1 ). 
Analisando as espécies individualmente, constatou-se que $63,34 \%$ dos indivíduos de $P$. pluviosa apresentaram problemas com rede elétrica, seguida pela $S$. molle, em que $34,6 \%$ dos seus indivíduos sob rede elétrica apresentaram conflitos. Em pesquisa realizada por Locastro et al. (2014), a espécie é responsável por 17,44\% dos conflitos aparentes com a rede elétrica, enquanto o trabalho realizado por Martins et al. (2011), apresentou a espécie $P$. pluviosa com uma das maiores incidências de interferência na rede elétrica, onde $93,15 \%$ dos indivíduos sob rede elétrica apresentaram algum tipo de interferência.

Em relação a S. molle, tanto o estudo de Locastro et al. (2014) como de Martins et al. (2011), diferentemente de Corumbataí do Sul, a espécie não esteve entre aquelas que apresentavam maiores incidências de conflito com a rede elétrica.

Desta forma, é estritamente necessário o estudo das espécies e de seus respectivos portes, para que o plantio seja realizado em locais ao qual a mesma venha interferir minimamente nos equipamentos urbanos e necessite de mínimo acompanhamento pelas prefeituras.

\section{Árvores e pedestres}

No levantamento foi registrada a presença de 28,8\% dos indivíduos com copas interferindo no trânsito de pedestres, sendo as espécies com maior relevância $S$. molle $(49,2 \%)$, Licania tomentosa (Benth) Fritsch (oiti) (12,2\%) e Hibiscus rosa-sinensis L. (hibisco) (7,57\%) (Tabela 1).

Esta interferência pode ser muitas vezes evitada quando os indivíduos arbóreos apresentam a altura da primeira bifurcação acima de 1,80 m. No caso de $H$. rosa-sinensis, essas interferências ocorrem devido ao fato da mesma possuir naturalmente hábito arbustivo, sendo a princípio, podada em viveiro, para que se adeque ao meio urbano. Entretanto, os indivíduos encontrados apresentavam primeira bifurcação abaixo de 1,80 m trazendo problemas à circulação dos pedestres. Neste contexto, o uso desta espécie torna-se inviável.

Mediu-se a altura da primeira bifurcação, constatando que $81 \%$ dos indivíduos apresentaram altura menor que 1,80 m, o que corrobora com o trabalho de Martins et al. (2011) na cidade de Luiziana (PR) onde $88 \%$ dos indivíduos apresentaram altura da primeira bifurcação inferior a 1,80 m. A espécie com maior número de indivíduos com altura da primeira bifurcação menor que $1,80 \mathrm{~m}$ em Corumbataí do Sul, foi $P$. pluviosa representando $43,4 \%$ dos indivíduos com esta característica, seguida de S. molle (20,49\%) e L. Iucidum (10,51\%). Foi constatado que S. molle apresentou maior interferência no trânsito de pedestres, pois 97,44\% de seus indivíduos apresentam ocorrência de bifurcação inferior a 1,80 m. Além disso, uma das principais características da espécie é a de possuir galhos pendentes, o que evidencia a 
necessidade constante de trabalhos de manutenção e condução, onerando seu manejo. No estudo de Martins et al. (2011), as espécies com maior frequência de altura da primeira bifurcação inferior a 1,80 $\mathrm{m}$ foram as mesmas que as encontradas em Corumbataí do Sul ( $P$. pluviosa, S. molle e L. Iucidum) e ainda, Tibouchina granulosa (Desr.) Cogn (quaresmeira).

\section{CONCLUSÕES}

Através do estudo realizado no município de Corumbataí do Sul, constatou-se predominância de algumas espécies arbóreas, sendo $P$. pluviosa, $S$ molle e L. lucidum as mais frequentes na arborização urbana, demonstrando a utilização de muitos indivíduos e poucas espécies.

Em relação à compatibilidade dos espécimes com equipamentos urbanos e as infraestruturas, observou-se que tais espécies, P. pluviosa, S. molle e L. lucidum, apresentaram maiores conflitos com rede elétrica, afloramento de raízes nas calçadas e copa interferindo no trânsito de pedestres, tornando evidente a inadequação destas espécies às condições locais, o que sugere a necessidade de manejo adequado da arborização visando o incremento de novas essências arbóreas.

Diante do exposto, ressalta-se a necessidade do desenvolvimento de pesquisas a fim de fornecer subsídios às autoridades municipais quanto ao planejamento adequado da arborização viária, propiciando o correto manejo com intuito de minimizar conflitos com equipamentos urbanos, obter menores custos com manutenção e reduzir transtornos à população.

\section{REFERÊNCIAS}

APG III, ANGIOSPERM PHYLOGENY GROUP. An update of the Angiosperm Phylogeny Group classification for the orders and families of flowering plants: APG III. Botanical Journal of the Linnean Society, London, v. 161, n. 2, p. 105-121, 2009.

BATISTEL, L. M.; DIAS, M. A. B.; MARTINS, A. S.; RESENDE, I. L. M. Diagnóstico qualitativo e quantitativo da arborização urbana nos bairros Promissão e Pedro Cardoso, Quirinópolis, Goiás. Revista da Sociedade Brasileira de Arborização Urbana, Piracicaba, v. 4, n. 3, p. 110-129, 2009.

BIONDI, D.; MACEDO, J. H. P. Plantas invasoras encontradas na área urbana de Curitiba (PR). Revista Floresta, Curitiba, v. 38, n. 1. p. 129-144, 2008. 
BLUM, C. T; BORGO, M; SAMPAIO, A. C. F. Espécies exóticas invasoras na arborização de vias públicas de Maringá - PR. Revista Brasileira de Arborização Urbana, Piracicaba - SP, v. 3, n. 2, p. 78-97, 2008.

BRUN, F. G. K.; FUCHS, R. H.; BRUN, E. J.; ARAÚJO, L. E. B. de. Legislações Municipais do Rio Grande do Sul referentes à arborização urbana - estudo de casos. Revista da Sociedade Brasileira de Arborização Urbana, Piracicaba, v. 3, n. 3, p. 44-64, 2008.

CAVIGLIONE, J. H.; KIIHL, L. R. B.; CARAMORI, P. H. OLIVEIRA, D. Cartas climáticas do Paraná. Londrina: IAPAR, 2000. CD-ROM.

HOPPEN, M. I.; DIVENSI, H. F.; RIBEIRO, R.F.; CAXAMBÚ, M. G. Espécies exóticas na arborização de vias públicas no município de Farol, PR, Brasil. Revista da Sociedade Brasileira de Arborização Urbana, Piracicaba, v. 9, n. 3, p. 173-186, 2014.

INSTITUTO PARANAENSE DE DESENVOLVIMENTO ECONÔMICO E SOCIAL (IPARDES). Caderno estatístico: Município de Corumbataí do Sul - Paraná. 2015. Disponível em:<http://www.ipardes.gov.br/cadernos/MontaCadPdf1.php?Municipio=86970\&btOk=0k> Acesso em: 03 nov. 2015.

LOCASTRO, J. K.; RASBOLD, G. G.; PERREIRA, J. S.R.; SOARES, B. S.; CAXAMBÚ, M. G. Censo da arborização urbana do município de Cafeara, Paraná. Revista da Sociedade Brasileira de Arborização Urbana, Piracicaba, v. 9, n. 3, p. 122-144, 2014.

MACHADO, R. R. B.; MEUNIER, I. M. J.; DA SILVA, J. A. A.; CASTRO, A. A. J. F. Árvores nativas para a arborização de Teresina, Piauí. Revista da Sociedade Brasileira de Arborização Urbana, Piracicaba, v. 1, n. 1, p. 10-18, 2006.

MARTINS, L. F. V.; ANDRADE, H. H. B.; HANISCH, R. F.; DE ANGELIS, B.L D.; CAXAMBU, M. G. Análise da compatibilidade da arborização viária com o ambiente construído na cidade de Luiziana, Paraná, Brasil. Revista da Sociedade Brasileira de Arborização Urbana, Piracicaba, v. 6, n. 3, p. 103-127, 2011.

MASCARÓ, L. E. A. R.; MASCARÓ, J. L. Vegetação urbana. 1a. ed. Porto Alegre: UFRGS FINEP, 2002.

MIRANDA, T. O. de; CARVALHO, S. M. Levantamento quantitativo e qualitativo de indivíduos arbóreos presentes nas vias do bairro da Ronda em Ponta Grossa - PR. Revista da Sociedade Brasileira de Arborização Urbana, Piracicaba - SP, v. 4, n. 3, p. 143-157, 2009.

MIRANDA, Y. C.; MACHADO, M de S.; SILVA, L dos S.; ESTEVAM, R.; MARTINS NETO, F. F.; CAXAMBU, M. G. Análise quali-quantitativa da arborização de ruas do município de Godoy Moreira - PR. Revista da Sociedade Brasileira de Arborização Urbana, Piracicaba - SP, v. 10, n. 1, p. 71-81, 2015.

PARANÁ, INSTITUTO AMBIENTAL DO PARANÁ (IAP). Portaria IAP n 59, de 15 de abril de 2015. Reconhece a lista oficial de espécies exóticas invasoras para o Estado do Paraná, estabelece normas de controle e dá outras providências. Diário Oficial do Estado do Paraná. Anexo 1. Curitiba, 2015. Disponível em: <celepar7.pr.gov.br/sia/atosnormativos/form_cons _ato1.asp?Codigo=2921 > Acesso em: 03 nov. 2015.

PIVETTA, K. F. L.; SILVA FILHO, D. F. Arborização urbana. Jaboticabal: Boletim Acadêmico (Série Arborização Urbana). UNESP/FCAV/FUNEP. 74p. 2002. 
RODERJAN, C. V.; GALVÃO, F; KUNIYOSHI, Y. S.; HATSCHBACH, G. As unidades fitogeográficas do Paraná. Ciência e Ambiente, Santa Maria, v. 24, n.1, p. 72-95, 2002.

SAMPAIO, A. C. F.; ANGELIS, B. L. D. de. Inventário e análise da arborização de vias públicas de Maringá - PR. Revista da Sociedade Brasileira de Arborização Urbana, Piracicaba, v. 3, n. 1, p. 37-57, 2008.

SARTORI, R. A; BALDERI, A. P. Inventário da arborização urbana do município de Socorro SP e proposta de um índice de danos à infra-estrutura das cidades. Revista da Sociedade Brasileira de Arborização Urbana, Piracicaba, v. 6, n. 4, p. 68-89, 2011.

SILVA, A. G.; GONÇALVES, W.; LEITE, H. G.; SANTOS E. Comparação de três métodos de obtenção de dados para avaliação quali-quantitativa da arborização viária, em Belo Horizonte MG. Revista da Sociedade Brasileira de Arborização Urbana, Piracicaba, v. 1, n. 1, p. 3144, 2006.

SILVA, M. D. M.; SILVEIRA, R. P.; TEIXEIRA, M. I. J. G. Avaliação da arborização de vias públicas de uma área da região oeste da cidade de Franca/SP. Revista da Sociedade Brasileira de Arborização Urbana, Piracicaba, v. 3, n. 1, p. 19-35, 2008. 